\title{
ADVANTAGES AND LIMITATIONS OF USING THE QFD METHOD IN THE PRODUCTION OF COPPER PRODUCTS - CASE STUDY
}

\author{
${ }^{1}$ Marta JAGUSIAK-KOCIK \\ ${ }^{1}$ Czestochowa University of Technology, Częstochowa, Poland, EU, \\ m.jagusiak-kocik@pcz.pl
}

https://doi.org/10.37904/metal.2020.3655

\begin{abstract}
In the paper customer preferences regarding copper wires were determined, special attention to the technical characteristics of wires were focused, that would meet customer expectations. To build a quality house, information from direct production employees as well as technologists and constructors were used. The application of the QFD method allowed of rendition of consumer requirements (customer voice) into technological parameters.
\end{abstract}

Keywords: Copper, wire products, quality, QFD method

\section{INTRODUCTION}

The QFD (Quality Function Deployment) method is Adjustment or Development of a Quality Function or Quality House. Thanks to this method, it is possible to rendition market requirements for the product into a set of conditions that must be met by the entity producing it at every stage of creation (from design through production to sales and service) $[1,2]$.

The fundamentals of the QFD method were developed by Y. Akao in 1966 as part of "Total Quality Control" $[3,4]$. Thanks to the QFD method, it can rationally design a product not only in technical terms, but also due to market requirements and customer expectations [5,6]. The QFD method is also used to improve logistics processes in the industry of metal production and metal processing $[7,8]$. QFD is also a factor motivating employees to promote quality $[9,10,17]$.

The main advantage of this method is the fact that already in the design phase you can take into account the voice of a potential customer, so that the final product can be better designed to meet customer requirements. This method is cost effective as well as relatively simple to implement, analyse and document. It can be used in all industries and services, as well as in administrative processes. Thanks to the QFD method, product planning becomes an integral part of quality planning, quality costs are better planned, and the product quality is constantly improved. The advantage of using this method is also lower production costs, as well as shortening production cycles. Additionally, the company can get to know better its weaknesses and strengths against the competition [1].

A certain limitation of this method is laborious and time consuming, which may cause resistance and reluctance to introduce it, as well as the absolute requirement of teamwork [16].

The QFD method is used in the preparation and production of new products and services, it is successfully used in the machine-building industry [19], automotive [20], chemical, pharmaceutical, construction [18], in credit institutions, as well as in the development of new computer systems [11,28]. It can also be used in the metal industry [12]. 


\section{AIM AND SCOPE OF RESEARCH}

The aim of the work is to use information from customers to analyse the QFD method to best adapt the product characteristics to the changing customers' requirements.

The product subject to analysis from the customer and manufacturer's point of view is copper wire, which is used for the production of insulated power cables. These cables are designed to transfer electricity from the source to the receiver. The basic components of these cables are: metal wires (enabling the flow of current from the source to the receiver, with the least possible losses), insulation of the wires (its task is to prevent direct contact a live wire with objects around the cable and other wires) and a protective coating (protecting the wires and insulation against mechanical damage and corrosive effects of the environment) [13].

It should be noted that the work is a pilot study, where the examined population is limited only to analysing the requirements of one enterprise. It is a medium-sized enterprise with headquarters in the Śląskie Voivodeship and involved in the production of electronic products. The enterprise in the production of its products, uses a large number of copper wires, which puts great emphasis on the high quality of such wires.

As the QFD method communicates the producer with customer, at work information concerning the basic assortment of several enterprises dealing in the production of copper products were used for the analysis. Due to the nature of research, where greater contact with the company is required, this is a limitation of this work.

\section{QFD ANALYSIS}

I. Customer requirements and grouping these requirements according to the relationship diagram.

At this stage, a representative group was selected that defined their requirements for copper wires used for the production of insulated copper power cables. The studied population was a group of direct production employees as well as technologists and constructors.

After selecting the population, collective lists were drawn up (3 lists of 20 employees) and 10 people were drawn from each of these lists. The result was the creation of a representative group of 30 people. This group was asked the question: What properties should copper wire have to produce high-quality insulated copper power cables? Respondents gave about 15 answers, of which 10 most common were chosen for further analysis - these properties (requirements) are presented below:
1) the price,
6) tensile strength,
2) high conductivity,
7) resistant to bending,
3) easy solderability,
8) high permissible operating
4) corrosion resistant, temperature,
5) flexible,
9) easy weldability,
10) low chemical activity.

In the quality house, shown in Figure 1, these requirements are placed in area 1.

In the next step, the properties of copper wires indicated by customers (direct production employees, technologists, and constructors) were ordered according to a new quality management tool - relationship diagram [14]. As a result of developing this diagram, five groups of requirements for copper wires were specified: electrical (high conductivity), mechanical (flexible, tensile strength and resistant to bending), chemical (corrosion resistant and low chemical activity), thermal (high permissible operating temperature) and other (the price, easy solderability and easy weldability).

II. Determining the importance of customer requirements.

At this stage, a representative group was asked to divide 50 points for each requirement for copper wires, thus determining the importance of each requirement. Distribution of points analysis showed that 
the most points were achieved by requirements related to price, high conductivity, easy solderability and flexibility. The requirement for resistant to bending and corrosion resistance has also proved to be quite important.

On the other hand, the least points were obtained by the requirements related to high permissible operating temperature and low chemical activity.

The next step of the QFD method is to determine the importance of customer requirements, in the adopted scale from 1 to 10 . The allocation of importance for individual requirements for copper wires is presented in area 2 in a quality house.

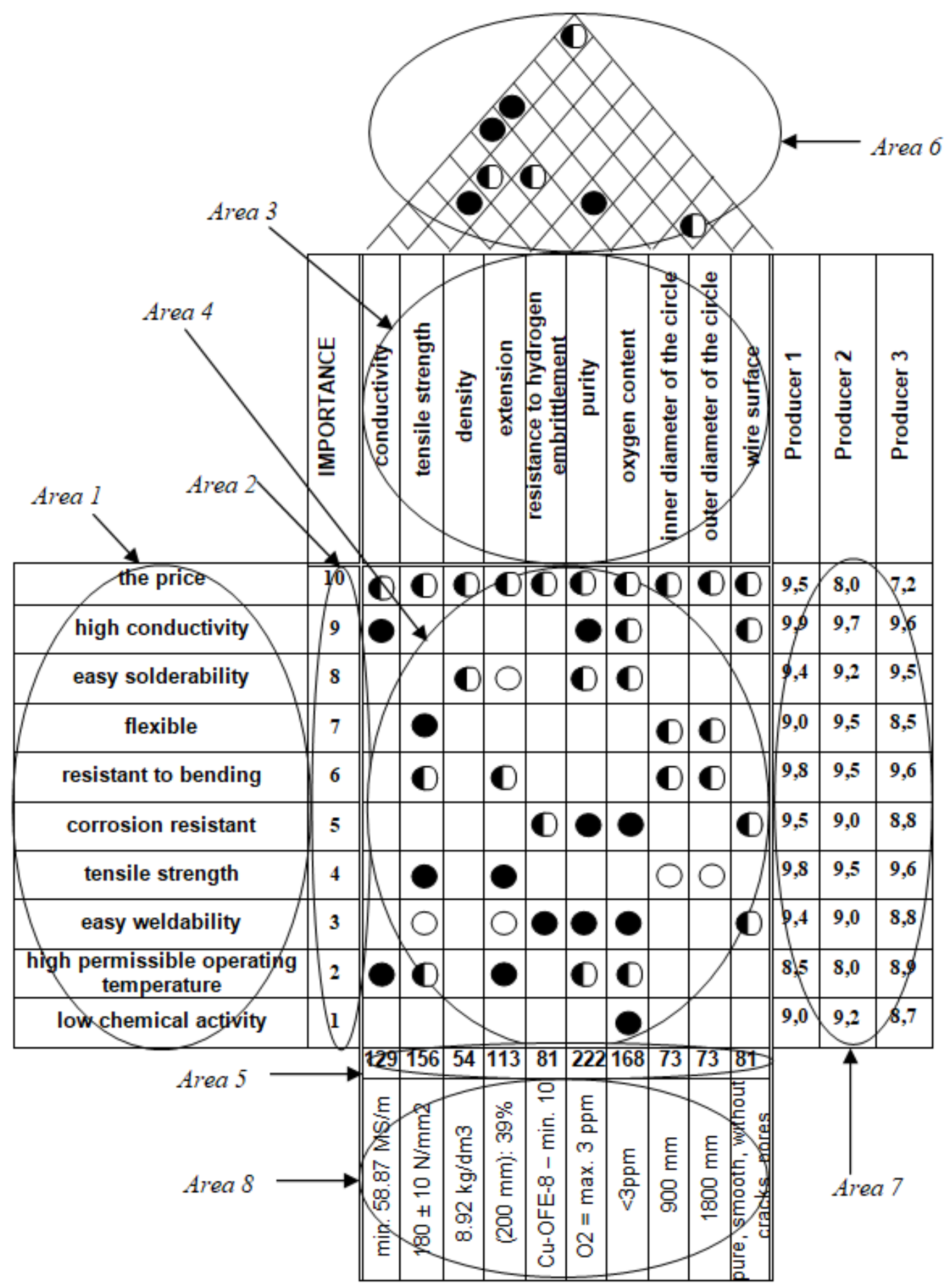

Figure 1 Graphic presentation of the QFD method - a house of quality for copper wires 
III. Determination of technical parameters of the selected product.

At this stage, the copper wires were characterized from the designer point of view by determining their technical parameters, which are presented below:

$\begin{array}{lll}\text { 1) conductivity, } & \text { 6) } & \text { purity, } \\ \text { 2) tensile strength, } & \text { 7) } & \text { oxygen content, } \\ \text { 3) density, } & \text { 8) } & \text { inner diameter of the circle, } \\ \text { 4) extension, } & \text { 9) } & \text { outer diameter of the circle, } \\ \text { 5) resistance to hydrogen embrittlement, } & \text { 10) } & \text { wire surface. }\end{array}$

The quality house in area 3 contains technical parameters.

IV. Relationships between customer requirements and technical parameters.

The following symbols are used in the example:

- strong relationship (9 points) $\quad$ D - medium relationship (3 points) $\bigcirc$ - weak relationship (1 point)

The relationships between customer requirements and technical parameters are shown in the middle part of the quality house (area 4).

V. Assessment of the importance of technical parameters.

Importance coefficients of technical parameters were calculated and presented in area 5 of the quality house.

VI. Determining the relationship between technical parameters.

The example uses symbols, as in the case of relationships between customer requirements and technical parameters. The relations between the technical parameters are presented in the roof of a quality house (area 6).

VII. Comparison of the product with the competition offer.

In the example, the offers of 3 companies producing copper wires were used. A representative group assessed each of the requirements by comparing 3 types of copper wires, giving grades from 1 to 10 , where 1 means unfulfilled requirement and 10 - fully fulfilled requirement. A comparison of copper wires from 3 companies in a quality home is presented in area 7.

VIII. Target technical parameters

In the analysed example, the target values of technical parameters are presented in the quality house in area 8.

\section{DISCUSSION AND CONCLUSIONS}

The paper presents the use of the QFD method for copper wire, used, among others in the production of insulated power cables.

After analysing and creating a quality home, it was shown that:

In terms of the importance of requirements, the respondents assessed that copper wires should be distinguished by their price, high conductivity and easy solderability. The price of copper as a strategic material is quite high and that's why customers are looking for a competitive price offer. High conductivity of copper wires is crucial in the production of electronic products that use insulated power cables. In the production of such products, the ease of soldering copper wires is also becoming very important. Easy solderability as a particularly desirable property in electrical systems, ensures the use of lead-free soldering technology, in accordance with the RoHS 2 Directive - Directive of the European Parliament and of the Council 2011/65/EU of 8 June 2011 on the restriction of the use of certain hazardous substances in electrical and electronic 
equipment [15]. The survey regarding the importance of respondents' requirements also shows that the mechanical requirement regarding flexibility and resistance to bending was assessed by the respondents as quite important in copper wires.

Analysing the middle part of the quality house, in which the relationships between customer requirements and technical parameters are highlighted, it can be stated that the strongest relationships occur between:

- $\quad$ high conductivity and conductivity (the same parameter from the customer and designer point of view),

- $\quad$ between conductivity and purity (defects and admixtures increase the resistivity),

- $\quad$ between flexibility and tensile strength (high flexibility and strength make copper an ideal material for electrical installations).

There is also a strong relationship between corrosion resistant and purity of copper wires and oxygen content (oxygen as a harmful admixture can reduce conductivity, ductility and corrosive properties). Tensile strength shows a strong relationship with extension, however in the case of easy weldability, a strong relationship with resistance to hydrogen embrittlement, purity and oxygen content is observed (in a copper weld that contains oxygen, many blisters are formed). In addition, there is a strong relationship between high permissible operating temperature and conductivity and extension (conductivity decreases with increasing temperature, moreover, extension with the effect of temperature changes leads to some problems with the conductors) and between low chemical activity and oxygen content (oxygen-containing copper is susceptible to damage during hot metal treatment under pressure).

The most important technical parameter from the designer point of view is parameter connected with copper purity. Copper is produced in such a way as to minimize the amount of admixtures and obtain the most homogeneous structure.

As a result of case study, some knowledge was obtained about the expectations of respondents (in this case employees of companies from the electronics industry), which may become the beginning of the main study covering a larger group of respondents or companies from other industries using copper wires in their production. It seems that this approach, focused on customer needs, can be particularly useful in those areas of industry and research in which highly specialized procedures cause a kind of "paternalization" of recipients, imposing on them a narrow understanding of quality and benefits, among others in the assembly of electronic devices [21], biotechnology [22], surface treatment with nanopowders [23] or laser beam [24,25]. Some aspects of this approach should be taken into account when building a statistical model by selecting the appropriate goal functions and related statistics, as they may affect sampling patterns, e.g. in ANOVA [26] or resampling bootstrap [27] tests.

\section{REFERENCES}

[1] WOLNIAK, R. The use of QFD method advantages and limitation. Production Engineering Archives. 2018, vol. 18, no. 18, pp. 14-17.

[2] CARNEVALLI, J.A., MIGUEL, P.C. Review, analysis and classification of the literature on QFD - Types of research, difficulties and benefits. International Journal of Production Economics. 2008, vol. 114, no. 2, pp. 737754. DOI: $10.1016 / j . j \mathrm{jpe} .2008 .03 .006$.

[3] AKAO, Y. QFD: Past, present and future. In International Symposium on OFD. Linköping, Sweden, 1997.

[4] CHAN, L-K., MING, L-W. Quality Function Deployment: A literature review. European Journal of Operational Research.2002, vol. 143, pp. 463-497.

[5] JOSHI, S., BHARGAVA, P. Waste Management Integration with Green Quality Function Deployment (G-QFD) for Healthcare Centre. Production Engineering Archives, 2019, vol. 22, no. 22, pp. 45-49.

[6] SUNDAY, A.O. Manufacturing Quality Function Deployment: Literature Review and Future Trends. Engineering Journal. 2012, vol. 17, no. 3, pp. 79-103. 
[7] NOWICKA-SKOWRON, M., ULEWICZ, R. Quality management in logistics processes in metal branch. In 24th International conference on metallurgy and materials, METAL 2015, pp. 1707-1712.

[8] ULEWICZ, R., SELEJDAK, J., BORKOWSKI, S., JAGUSIAK-KOCIK, M., Process management in the cast iron foundry. In 22nd International conference on metallurgy and materials, METAL 2013, pp. 1926-1931.

[9] GRABARA, J., CEHLAR, M., DABYLOVA, M. Human factor as an important element of success in the implementation of new management solutions. Polish Journal of Management Studies. 2019, vol. 20, no. 2, pp. 225-235.

[10] PACANA, A.; ULEWICZ, R. Research of determinants motiving to implement the environmental management system. Polish Journal of Management Studies. 2017, Vol. 16 no. 1, pp. 165-174.

[11] WIŚNIEWSKA, M. House of Quality jako narzędzie planowania i rozwoju stanowiska pracy. Problemy Jakości. 2006, no. 6, pp. 20-26.

[12] LAGER, T. Contemporary Quality Function Deployment For Product And Process Innovation. Towards Digital Transformation of Customer and Product Information in a New Knowledge-Based Approach. Singapore: World Scientific Publishing Co Pte, 2020.

[13] CELIŃSKI, Z. Materiałoznawstwo elektrotechniczne. Warszawa: Oficyna Wydawnicza Politechniki Warszawskiej, 2018.

[14] JAGUSIAK-KOCIK, M. Aplikacyjność metody QFD w dostosowaniu małego AGD - Case study. Praktyczne aspekty zarządzania produkcją i bezpieczeństwem. Kraków: Politechnika Krakowska, 2019.

[15] EUR-Lex Access to European Union Law [online]. [viewed 2020-05-14]. Available from:https://eurlex.europa.eu/legal-content/EN/TXT/?uri=CELEX:02011L0065-20200501

[16] WOLNIAK, R. Historia metody QFD. Zeszyty naukowe Politechniki Śląskiej. Seria Organizacja i zarządzanie. 2017, vol. 100, pp. 553-564.

[17] WOJTASIK, K. New Impulse, New Challenges. Safety Procedures in a Production Enterprise. A Case Study. System Safety: Human - Technical Facility - Environment. 2020, vol. 2, pp. 26-32.

[18] KNOP, K., ULEWICZ, R. Assessment of technology, technological resources and quality in the manufacturing of timber products. Digitalisation and Circular Economy: Forestry and Forestry Based Industry Implications. 2019, pp. 251-256.

[19] KRYNKE, M., KANIA, L., MAZANEK, E. Modelling the contact between the rolling elements and the raceways of bulky slewing bearings. Key Engineering Materials. 2012, vol. 490, pp. 166-178.

[20] MAZUR M. Analysis of production incompatibilities and risk level in series production of assembly elements for the automotive industry. In MATEC Web of Conferences. 2018, vol. 183.

[21] PIETRASZEK, J., GADEK-MOSZCZAK, A., TORUNSKI, T. Modeling of Errors Counting System for PCB Soldered in the Wave Soldering Technology. Advanced Materials Research. 2014, vol. 874, pp. 139-143.

[22] SKRZYPCZAK-PIETRASZEK, E., KWIECIEN, I., GOLDYN, A. PIETRASZEK, J. HPLC-DAD analysis of arbutin produced from hydroquinone in a biotransformation process in Origanum majorana $L$. shoot culture.

Phytochemistry Letters. 2017, vol. 20, pp. 443-448. KORZEKWA, J., BARA, M., PIETRASZEK, J. and PAWLUS, P. Tribological behaviour of Al2O3/inorganic fullerene-like WS2 composite layer sliding against plastic. International Journal of Surface Science and Engineering. 2016, vol. 10, pp. 570-584.

[23] RADEK, N., BARTKOWIAK, K. Laser treatment of electro-spark coatings deposited in the carbon steel substrate with using nanostructured WC-Cu electrodes. Physics Procedia. 2012, vol. 39, pp. 295-301.

[24] GADEK-MOSZCZAK, A., RADEK, N., WRONSKI, S., TARASIUK, J. Application the 3D Image Analysis Techniques for Assessment the Quality of Material Surface Layer Before and After Laser Treatment. Advanced Materials Research. 2014, vol. 874, pp. 133-138.

[25] PIETRASZEK, J., KOLOMYCKI, M., SZCZOTOK, A., DWORNICKA, R. The Fuzzy Approach to Assessment of ANOVA Results. Lecture Notes in Artificial Intelligence. 2016, vol. 9875, pp. 260-268.

[26] PIETRASZEK, J., GADEK-MOSZCZAK, A. The Smooth Bootstrap Approach to the Distribution of a Shape in the Ferritic Stainless Steel AISI 434L Powders. Solid State Phenomena. 2012, vol. 197, pp. 162-167.

[27] INGALDI, M., ULEWICZ, R. Evaluation of quality of the e-commerce service. International Journal of Ambient Computing and Intelligence. 2018, vo. 9, no.2, pp. 55-66. 